\title{
Protistan diversity does peak in the horohalinicum of the Baltic Sea: Reply to Ptacnik et al. (2011)
}

\author{
Irena V. Telesh ${ }^{1, *}$, Hendrik Schubert ${ }^{2}$, Sergei O. Skarlato ${ }^{3}$ \\ ${ }^{1}$ Zoological Institute, Russian Academy of Sciences, 199034 Saint Petersburg, Russia \\ ${ }^{2}$ Institute of Biological Sciences, University of Rostock, 18051 Rostock, Germany \\ ${ }^{3}$ Institute of Cytology, Russian Academy of Sciences, 194064 Saint Petersburg, Russia
}

\begin{abstract}
In reply to the Comment by Ptacnik et al. (2011; Mar Ecol Prog Ser 432:291-292), a substantiation is given for the use of the simplest method to conduct a meta-analysis of published plankton data sets and annotated checklists aimed at refining the 'Artenminimum' (species-minimum) concept (Remane 1934; Zool Anz 7(Suppl):34-74). The applicability of this concept, which originally derived from macrozoobenthos data, was tested by Telesh et al. (2011; Mar Ecol Prog Ser 421:1-11) for plankton species using much larger data sets, and these results backed up the novel 'protistan species-maximum concept' for the horohalinicum of the Baltic Sea. Re-fitting our algorithm to the available data sets after the critical comments of Ptacnik et al. (2011) did not alter the shape of the plankton diversity trends, and the original conclusions that (1) the brackish-water Baltic Sea is not poor in plankton species, (2) Remane's curve is invalid for plankton, and (3) protistan species richness peaks in the horohalinicum at salinities of 5 to 8 remained robust. The suggestion by Ptacnik et al. (2011) to use a more detailed statistical analysis for describing the patterns of overall plankton diversity is recognized as a perspective for future research of changes in plankton communities within the Baltic Sea salinity gradient, although it cannot be implemented until spatially representative zooplankton data sets become available.
\end{abstract}

KEY WORDS: Plankton diversity $\cdot$ Protistan species-maximum concept $\cdot$ Salinity $\cdot$ Horohalinicum Remane's curve · Baltic Sea

In Telesh et al. (2011) we reported a substantial increase in protistan diversity at salinities of 5 to 8 in the horohalinicum of the Baltic Sea. This finding challenges the broadly accepted brackish-water biodiversity pattern known as the 'Artenminimum' (speciesminimum) concept, developed by Remane (1934, his Fig. 1). This concept was derived from macrozoobenthos data of the Baltic Sea and has been textbook knowledge for decades (e.g. Kinne 1971, Remmert 1989, Lalli \& Parsons 1997, McLusky \& Elliott 2004), playing a key role in characterizing the Baltic Sea as a 'species-poor basin'. We reassessed overall plankton diversity in the Baltic Sea, refined Remane's concept by showing its inapplicability to plankton, proposed a new 'protistan species-maximum concept' and dismissed the outdated viewpoint that the Baltic Sea is poor in plankton species (Telesh et al. 2011).

Ptacnik et al. (2011), in their thoughtful Comment on our article concerning protistan diversity trends in the Baltic Sea, dispute that the analysis performed in Telesh et al. (2011) allows conclusions regarding the pattern of plankton diversity along the freshwatermarine continuum. They particularly claim that our analysis is biased because species lists were pooled 
within salinity bands, which may create patterns that are due to methodology. We welcome the opportunity to clarify key aspects of our analysis.

\section{To pool or not to pool?}

Scientific generalizations are often based on analyses of large heterogeneous data sets, which may be incomparable due to methodological discrepancies, non-random sampling and other inconsistencies. It is generally accepted that ongoing observations of marine ecosystems and prudent examination of historical data sets are both needed (Boyce et al. 2011, Mackas 2011, McQuatters-Gollop et al. 2011, Rykaczewski \& Dunne 2011). Although every statistical analysis requires data obtained by random sampling, in reality ecologists rarely sample the individual organisms randomly (Gotelli \& Colwell 2001). However, despite considerable differences in scales, approaches, methodology and philosophy behind any particular research, large-scale biodiversity estimates using historical and modern data are a necessaryalbeit elusive - prerequisite to understanding macroecological changes that define biodiversity patterns and ecosystem functioning (Falkowski et al. 1998, Raitsos et al. 2005, Behrenfeld et al. 2006, Martinez et al. 2009, Boyce et al. 2010, 2011, Ojaveer et al. 2010).

Thus, the dilemma often arises: either to pool the available data and perform an analysis to acquire realistic results or to ignore the vast, though methodologically outdated knowledge gained by previous generations of scientists. This challenge is often resolved in favor of statistical transformation of the irregular, nonuniform, or incomplete historic data sets to match the modern ones (e.g. Boyce et al. 2010). For example, depending upon the scale of interest or the focus of research, a group of e.g. individual-based data sets or mass samples can be analysed as if they were replicate samples from the same statistical universe (e.g. Grassle \& Maciolek 1992). Likewise, it is standard practice to pool a set of replicated samples and to treat them as a single data set for some purposes (Engstrom \& James 1981, Gotelli \& Colwell 2001).

The main purpose of our study (Telesh et al. 2011) was to consider the numbers of plankton species in the salinity gradient of the Baltic Sea against the background of Remane's curve for macrozoobenthos and to evaluate the applicability of Remane's species-minimum concept to plankton. To achieve this goal, we used the same approach as Remane (1934): (1) we pooled the numbers of plankton species from different salinity ranges after we had performed meta-analyses of several extended data sets on phytoplankton and zooplankton in the Baltic Sea, and (2) we re-estimated the updated numbers of species and higher taxa following the present-day synonymy (Telesh et al. 2011 and references therein). Although these data sets originate from various sources (cited in Telesh et al. 2011, p. 3-5) and have different resolution, standardization was achieved years ago (e.g. HELCOM 1988, 2001, Harris et al. 2000; see Telesh et al. 2011, p. 4).

To better compare our results with Remane's curve, we used the same method and metrics as Remane (1934), who pooled numbers of macrozoobenthos species and higher taxa for different salinity ranges. The original Remane's curve, as well as its modification based on an extended data set (Remane 1958), were created by pooling ca. 400 macrozoobenthos taxa of the Baltic Sea (including the Öresund) into 5 salinity classes. Before this, Johansen et al. (1918; used by Remane 1934 for refining his curve), employed 10 unequal salinity classes for pooling data collected in the Randers Fjord. Therefore, Telesh et al. (2011) performed a robust and unbiased comparison of protistan diversity trends with appropriate reference data, likewise collected in the Baltic coastal regions and inlets as was the case for Johansen et al. (1918) and Remane (1934, 1958). Moreover, Remane (1958) assumed that the distribution of protists and some phytoplankton groups might be different from that of the macrofauna, because he referred to the work of Hustedt (1925) and Kahl (1928), which showed that the number of diatom and ciliate species increases with salinity to a certain point, after which the number of species declines with further increasing salinity (Remane 1958, p. 25).

With respect to the resolution of the salinity data, our approach of pooling taxa within salinity intervals of 1 (cf. Fig. 2C in Telesh et al. 2011) allowed a substantially higher resolution and, consequently, contains less bias than the data in Remane (1934), which were classified in salinity intervals of 5 . Therefore, we maintain that our analysis used adequate methods and provided adequate results (Telesh et al. 2011). Hence, pooling the existing data on phytoplankton and zooplankton species richness in the Baltic Sea allowed us to draw conclusions that were supported also by earlier observations on the inapplicability of Remane's concept to different communities in other brackish water bodies (e.g. Boesch et al. 1976, Attrill 2002, Muylaert et al. 2009).

Nevertheless, we welcome the critical suggestions of Ptacnik et al. (2011) and concur with their opinion that calculation of e.g. smoothed rarefaction curves and accumulation curves for certain plankton groups would be useful. Application of these statistical methods to the homogenous data sets (when available) would be helpful for future assessments of the spatial distribution of plankton and the identification of 'biogeographic provinces' in the Baltic Sea, e.g. at local or regional levels or as conducted by Olli et al. (2011). 


\section{Spatial coverage and availability of data}

Ptacnik et al. (2011) question the validity of the richness patterns in Telesh et al. (2011), which were largely derived from coastal sites, claiming that those are not representative of the open Baltic Sea. This may be true if the latter term refers to the deep-sea Baltic Proper, the plankton diversity of which is not well known, because HELCOM monitoring data for this region are restricted to dominant species. Nevertheless, these monitoring data, although they usually have lower taxonomic resolution, contribute significantly to the newly discovered protistan diversity pattern, as the salinity of the Baltic Proper falls into the horohalinicum range (Feistel et al. 2008). Future expansions of plankton data sets for the Baltic Proper would facilitate biodiversity analyses with more complete coverage. However, present-day spatial coverage and taxonomic resolution allow us to conclude that the Baltic Sea is by no means 'poor in plankton species'. By comparison, Hoppenrath (2004) lists 227 phytoplankton species for the North Sea around Helgoland, and Hallegraeff \& Jeffrey (1984) list a similar number of taxa for north and northwest Australia. In both articles, higher taxa are included in the analysis, because some species could not be identified below genus level, and therefore the true number of species in these basins should be higher. In the data set from the horohalinicum of the SW Baltic Sea we found ca. 300 phytoplankton taxa at each salinity interval of 1 , about 140 of which were identified to the species level. Using salinity intervals of 5, which are more comparable to the data from Hallegraeff \& Jeffrey (1984) and Hoppenrath (2004) increases the number of taxa per salinity class, thus confirming that phytoplankton diversity in marine and brackish Baltic regions is high.

Moreover, the coastal zone and coastal inlets are important with respect to spatial biodiversity coverage, as well as their function as 'bioreactors' that convert terrestrial nutrient runoff into biomass and thus 'feed' the sea (Schiewer 2008). Coastal plankton communities are largely representative of many Baltic habitats, including the Baltic Proper, due to hydrodynamic exchange processes (Telesh 2004, Schiewer 2008, Telesh et al. 2009). Moreover, the species-rich lowsalinity and freshwater areas in estuaries and gulfs are also parts of the Baltic Sea (Schiewer 2008, Telesh \& Khlebovich 2010) and have to be considered. However, in our article (Telesh et al. 2011), we were not targeting a spatial analysis of plankton species distribution in the Baltic Sea, largely because of the fact that the background data for such analyses are insufficient so far, or just lacking for a number of groups of plankton organisms (e.g. ciliates) in certain areas (Telesh et al. 2008, 2009, Mironova et al. 2009).

\section{Species-area correlation versus effect of sampling effort}

Ptacnik et al. (2011) surmise that the peak in plankton diversity in Telesh et al. (2011, their Fig. 2C) seems to stem largely from the peak in sampling effort. However, the curve with numbers of Criptophyta species in the same graph (broken line in Fig. 2C) peaks at salinity of about 16, which cannot be explained by sampling effort alone, as it is completely different from the sampling frequency maximum at salinity of 8 .

With respect to temporal aspects of the sampling effort, we reanalyzed the data set for seasonal coverage (Fig. 1). The gap in January and February as well as the limited number of samples in December correspond to the period of ice cover, when the productivity of the system is low (e.g. Schumann et al. 2005, Schubert \& Wasmund 2005). Although some flagellates can bloom under the ice, species diversity in winter is lower than during the vegetation season (Schumann et al. 2005). Throughout the rest of the annual cycle, the database we used is balanced, taking into account that Fig. 1 represents more than 3000 data sub-sets, each one consisting of a species list for each sample taken at particular date and locality over 15 yr (1986 through 1999; Sagert et al. 2008).

The range covered by the database described in Sagert et al. (2008) extends up to a salinity of 29; however, the columns above salinity 23 cannot be seen in Fig. 2C of Telesh et al. (2011) due to the scaling problem: only 1 sampling case is available for salinity 29, while the most frequent class of salinity 8 consists of 588 cases. Some of the higher salinity classes are 'empty'. However, having salinity 29 as the highest class, we performed an interpolation, not an extrapolation as assumed by Ptacnik et al. (2011). To illustrate this, we have re-arranged the data shown in Fig. $2 \mathrm{C}$ of

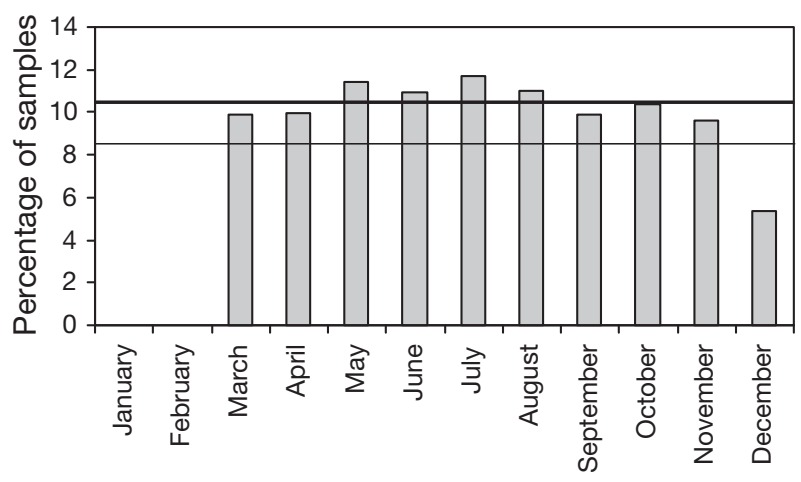

Fig. 1. Temporal distribution of sampling effort (percentage of samples collected per month) for the phytoplankton data set in Sagert et al. (2008) analysed in Telesh et al. (2011). The thin line $(8.3 \%)$ represents the mean for a 12 mo period; the thick line $(10.2 \%)$ represents the mean excluding the 3 winter months 
Telesh et al. (2011) excluding all salinity classes represented by $<10$ samples, and adding the curve for dinophytes, where species numbers are highest at salinities $>15$, irrespective of the lower sampling density (Fig. 2).

\section{Effect of salinity on plankton diversity}

Ptacnik et al. (2011) assert that the data in Telesh et al. (2011) suggest highest diversity of plankton at 'intermediate salinities', following a species-area relationship and fitting well with the null hypothesis that 'salinity itself has no effect on plankton diversity' (Ptacnik et al. 2011, p. 292). This supports our idea that planktonic protists with their high salinity tolerance (e.g. Stock et al. 2002) are generally not affected by salinity stress in the horohalinicum within the Baltic Sea gradient (Telesh et al. 2011). Assuming that the 'intermediate salinities' (the exact range of which is not specified in Ptacnik et al. 2011) correspond to the horohalinicum salinities of 5 to 8 , as in Telesh et al. (2011), we agree with the points made by Ptacnik and colleagues as far as protists are concerned. Indeed, our results show that salinity within this range has no major stressful effect on the diversity of ciliates and phytoplankton; nevertheless, this might not apply to plankton diversity in general, as affirmed by Ptacnik et al. (2011).

Other explanations for the observed species maximum patterns are discussed in Telesh et al. (2011), e.g. the Intermediate Disturbance Hypothesis proposed by Grime (1973). Ongoing studies should eventually explain why the small-sized, rapidly evolving protists peak in the horohalinicum of the brackish-water Baltic Sea.

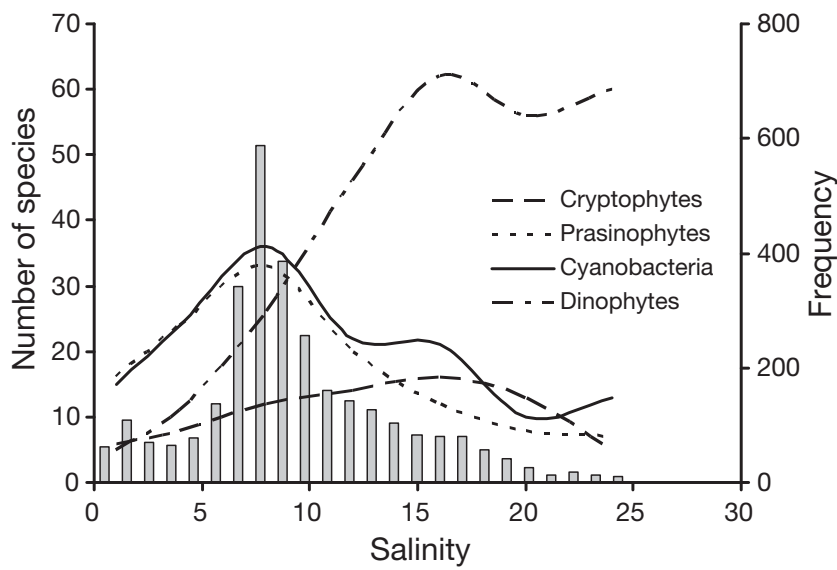

Fig. 2. Number of cryptophyte, prasinophyte, cyanobacteria and dinophyte species recorded in samples from sites with different salinities along the German Baltic coast (data from Sagert et al. 2008); bars (right $y$-axis) indicate the frequency of occurrence of sites with the respective salinity (note different scales on left $y$-axis here and in Fig. $2 \mathrm{C}$ in Telesh et al. 2011). Only salinity classes consisting of at least 10 sampling cases are included
Acknowledgements. Research at the Ulrich Schiewer Experimental Laboratory for Aquatic Cytoecology was supported by the International Bureau of the German Federal Ministry of Education and Research (Project RUS 09/038) and the Russian Foundation for Basic Research (projects 10-04-00943, 11-04-00053).
> Attrill MJ (2002) A testable linear model for diversity trends in estuaries. J Anim Ecol 71:262-269

- Behrenfeld MJ, O'Malley RT, Siegel DA, McClain C and others (2006) Climate-driven trends in contemporary ocean productivity. Nature 444:752-755

> Boesch DF, Diaz RJ, Virnstein RW (1976) Effects of Tropical Storm Agnes on soft-bottom macrobenthic communities of the James and York estuaries and the lower Chesapeake Bay. Chesap Sci 17:246-259

> Boyce DG, Lewis MR, Worm B (2010) Global phytoplankton decline over the past century. Nature 466:591-596

> Boyce DG, Lewis MR, Worm B (2011) Boyce et al. reply. Nature 472:E8-E9. doi:10.1038/nature09953

Engstrom RT, James FC (1981) Plot size as a factor in winter bird-population studies. Condor 83:34-41

Falkowski PG, Barber RT, Smetacek V (1998) Biogeochemical controls and feedbacks on ocean primary production. Science 281:200-206

Feistel R, Feistel S, Nausch G, Szaron J, Lysiak-Pastuszak E, Ærtebjerg G (2008) BALTIC: monthly time series 19002005. In: Feistel R, Nausch G, Wasmund N (eds) State and evolution of the Baltic Sea, 1952-2005. John Wiley \& Sons, Hoboken, p 311-336

Gotelli NJ, Colwell RK (2001) Quantifying biodiversity: procedures and pitfalls in the measurement and comparison of species richness. Ecol Lett 4:379-391

Grassle JF, Maciolek NJ (1992) Deep-sea species richness: regional and local diversity estimates from quantitative bottom samples. Am Nat 139:313-341

Grime JP (1973) Competitive exclusion in herbaceous vegetation. Nature 242:344-347

Hallegraeff GM, Jeffrey SW (1984) Tropical phytoplankton species and pigments of continental shelf waters of North and North-West Australia. Mar Ecol Prog Ser 20:59-74

Harris RP, Wiebe PH, Lenz J, Skjoldal HR, Huntley M (eds) (2000) ICES zooplankton methodology manual. Academic Press, San Diego

HELCOM (1988) Guidelines for the Baltic Monitoring Programme for the Third Stage. Part D. Biological determinants. Baltic Sea Environ Proc 27D. Helsinki Commission, Helsinki

HELCOM (2001) Environment of the Baltic Sea area 19941998. Baltic Sea Environ Proc 82A. Helsinki Commission, Helsinki

> Hoppenrath M (2004) A revised check-list of planktonic diatoms and dinoflagellates from Helgoland (North Sea, German Bight). Helgol Mar Res 58:243-251

Hustedt F (1925) Bacillariales aus den Salzgewässern bei Oldesloe in Holstein. Mitt Geogr Ges Nathist Mus Lübeck 30:84-120

Johansen AC, Ditlevsen H, Heerfordt F, Jacobsen JP and others (1918) Randers Fjords Naturhistorie. Carlsbergfondet, København, I kommission hos CA Reitzel

Kahl A (1928) Ciliata der Oldesloer Salzwasserquellen. Arch Hydrobiol 19:50-123

Kinne O (ed) (1971) Marine ecology, Vol 1, Part 2. Wiley Interscience, London 
Lalli CM, Parsons TR (1997) Biological oceanography. Butterworth-Heinemann, Oxford

Mackas DL (2011) Does blending of chlorophyll data bias temporal trends? Nature 472. doi:10.1038/nature09951

Martinez E, Antoine D, D'Ortenzio F, Gentili B (2009) Climate-driven basin-scale decadal oscillations of oceanic phytoplankton. Science 326:1253-1256

McLusky DS, Elliott M (2004) The estuarine ecosystem: ecology, threats and management, 3rd edn. Oxford University Press, Oxford

McQuatters-Gollop A, Reid PC, Edwards M, Burkill PH and others (2011) Is there a decline in marine phytoplankton? Nature 472. doi:10.1038/nature09950

Mironova EI, Telesh IV, Skarlato SO (2009) Planktonic ciliates of the Baltic Sea. Inland Water Biol 2:13-24

Muylaert K, Sabbe K, Vyverman W (2009) Changes in phytoplankton diversity and community composition along the salinity gradient of the Schelde Estuary (Belgium/The Netherlands). Estuar Coast Shelf Sci 82:335-340

Ojaveer H, Jaanus A, MacKenzie BR, Martin G and others (2010) Status of biodiversity in the Baltic Sea. PLoS ONE 5:e12467

Olli K, Klais R, Tamminen T, Ptacnik R, Andersen T (2011) Long term changes in the Baltic Sea phytoplankton community. Boreal Environ Res 16(Suppl A):3-14

Ptacnik R, Olli K, Lehtinen S, Tamminen T, Andersen T (2011) Does plankton diversity peak at intermediate salinities? Comment on Telesh et al. (2011) Mar Ecol Prog Ser 432: 291-292

Raitsos DE, Reid PC, Lavender SJ, Edwards M, Richardson AJ (2005) Extending the SeaWiFS chlorophyll data set back 50 years in the northeast Atlantic. Geophys Res Lett 32: L06603

Remane A (1934) Die Brackwasserfauna. Zool Anz 7(Suppl): $34-74$

Remane A (1958) Ökologie des Brackwassers. In: Remane A, Schlieper C (eds) Die Biologie des Brackwassers. Binnen-

Editorial responsibility: Matthias Seaman, Oldendorf/Luhe, Germany gewässer 22:1-216

Remmert H (1989) Ökologie. Springer-Verlag, Berlin

Rykaczewski RR, Dunne JP (2011) A measured look at ocean chlorophyll trends. Nature 472. doi:10.1038/nature09952

Sagert S, Rieling T, Eggert A, Schubert H (2008) Development of a phytoplankton indicator system for the ecological assessment of brackish coastal waters (German Baltic Sea coast). Hydrobiologia 611:91-103

Schiewer U (ed) (2008) Ecology of Baltic coastal waters. Springer-Verlag, Berlin

Schubert H, Wasmund N (2005) Das Phytoplankton des Strelasundes und des Kubitzer Boddens. Meer Mus 18:83-91

> Schumann R, Hammer A, Görs S, Schubert H (2005) Winter and spring phytoplankton composition and production in a shallow eutrophic Baltic lagoon. Estuar Coast Shelf Sci 62:169-181

Stock C, Grønlien HK, Allen RD, Naitoh Y (2002) Osmoregulation in Paramecium: in situ ion gradients permit water to cascade through the cytosol to the contractile vacuole. J Cell Sci 115:2339-2348

Telesh IV (2004) Plankton of the Baltic estuarine ecosystems with emphasis on Neva Estuary: a review of present knowledge and research perspectives. Mar Pollut Bull 49:206-219

Telesh IV, Khlebovich VV (2010) Principal processes within the estuarine salinity gradient: a review. Mar Pollut Bull 61:149-155

Telesh I, Postel L, Heerkloss R, Mironova E, Skarlato S (2008) Zooplankton of the open Baltic Sea: atlas. BMB Publ 20. Meereswiss Ber 73:1-251

Telesh I, Postel L, Heerkloss R, Mironova E, Skarlato S (2009) Zooplankton of the open Baltic Sea: extended atlas. BMB Publ 21. Meereswiss Ber 76:1-290

Telesh IV, Schubert H, Skarlato SO (2011) Revisiting Remane's concept: evidence for high plankton diversity and a protistan species maximum in the horohalinicum of the Baltic Sea. Mar Ecol Prog Ser 421:1-11

Submitted: May 9, 2011; Accepted: May 19, 2011

Proofs received from author(s): June 3, 2011 